\title{
A VISÃO DOS PRECEPTORES A RESPEITO DA RESIDÊNCIA MULTIPROFISSIONAL COM FOCO NA ORTOPEDIA E TRAUMATOLOGIA NO INTERIOR DA AMAZÔNIA
}

\author{
Monique Natálle Silva Pereira ${ }^{1}$ \\ Jorge Carlos Menezes Nascimento Junior2 \\ Edna Ferreira Coelho Galvão 3
}

\section{RESUMO}

A nova constituição do conceito de saúde e de assistência à saúde baseada nos princípios da universalidade, integralidade, equidade, intersetorialidade, humanização do atendimento e participação social propostas pelo Sistema único de Saúde têm requerido a reformulação da atuação dos diversos atores que compõem o quadro da atenção à saúde para que a assistência ao usuário seja pautada na atuação multiprofissional. A pesquisa busca avaliar a percepção sobre o processo de ensino aprendizagem desenvolvido no contexto da Ortopedia e Traumatologia entre preceptores inseridos na Residência Multiprofissional em Saúde na Atenção Integral em Traumatologia e Ortopedia. Trata-se de um estudo quantitativo, descritivo e transversal realizado com 29 preceptores através da aplicação de um questionário formulado pelos autores da pesquisa. Os dados foram tratados no Microsoft Excel Office 2013 e teste Qui-quadrado no Bioestat 5.3 com $\mathrm{p} \leq 0.05$. Nos resultados, $72,4 \% ; \mathrm{n}=21$ respondeu "Não" quando questionados se tiveram acesso ao Projeto Político Pedagógico (PPP) e a parcela de 93,1\%; n=27 acreditam que a Residência está voltada para o fortalecimento dos princípios e diretrizes do SUS. Portanto, o processo de ensino aprendizagem da Residência Multiprofissional possui pontos positivos assim como algumas lacunas em sua estrutura que podem ser minimizadas através da organização e entrosamento entre a equipe envolvida no programa, para que o ensino e aprendizagem seja um instrumento de mudança na oferta de saúde de qualidade à comunidade.

Palavras-chave: Residência. Multiprofissional. Preceptores.

\footnotetext{
1 Fisioterapeuta Residente na Residência Multiprofissional em Saúde na área de Atenção Integral em Ortopedia e Traumatologia (Universidade do Estado do Pará - UEPA). Pós graduanda em Saúde Pública com ênfase em saúde da família (UNINTER). E-mail: natallepereira@yahoo.com.br

2 Mestrando em Ensino em Saúde na Amazônia (Universidade do Estado do Pará). Professor substituto do curso de Fisioterapia (Universidade do Estado do Pará - UEPA). E-mail: jcmnj@hotmail.com

3 Doutora em Educação (Universidade Federal Fluminense). Professora do curso de Educação Física (Universidade do Estado do Pará - UEPA). E-mail: efcgalvao@gmail.com
} 


\title{
THE VISION OF THE PRECEPTORS ABOUT THE EXPERIENCE OF MULTIPROFESSIONAL RESIDENCE WITH FOCUS ON ORTHOPEDICS AND
}

TRAUMATOLOGY IN THE MIDST OF AMAZON

\begin{abstract}
The new constitution of the concept of health and health care based on the principles of universality, totality, equity, intersectionality, humanization of care and social participation proposed by the Unified Health System (SUS) have required the reformulation of the performance of the various actors that make up the framework of the attention to health so that user assistance is based on multiprofessional work. The research seeks to evaluate the perception about the process of teaching/ learning developed in the context of Orthopaedics and Traumatology between preceptors inserted in the Multiprofessional Health Residency in Integral Care in Traumatology and Orthopaedics. It is a quantitative, descriptive and cross-sectional study carried out with 29 preceptors through the application of a questionnaire formulated by the authors of the research. Data were treated in Microsoft Excel Office 2013 and Chi-square test in Bioestat 5.3 with $p \leq 0.05$. In the results, $72,4 \% ; n=21$ answered "No" when asked if they had access to the Political Pedagogical Project (PPP) and the portion of 93,1\%; $n=27$ believe that the Residency is focused on strengthening SUS principles and guidelines. Therefore, the learning process of the Multiprofessional Residency has positive points as well as some gaps in its structure that can be minimized through the organization and interaction between the team involved in the program, so that teaching and learning can become an instrument of change in the provision of quality health to the community.
\end{abstract}

Keywords: Residence. Multiprofessional. Preceptors.

\section{LA VISIÓN DE LOS PRECEPTORES ACERCA DE LA RESIDENCIA MULTIPROFESIONAL CON FOCO EN LA ORTOPEDIA Y TRAUMATOLOGÍA EN EL INTERIOR DE LA AMAZONIA}

\section{RESUMEN}

La nueva constitución del concepto de cuidado de la salud y de la salud basado en los principios de universalidad, integralidad, equidad, intersectorialidad, la humanización del servicio y la participación social propuesto por el Sistema de Salud han requerido la reformulación del papel de los diferentes actores en el marco del cuidado de la salud para la asistencia al usuario a ser guiado por el rendimiento multi-profesional. La investigación tiene como objetivo evaluar la percepción del proceso de enseñanza y aprendizaje desarrollado en el contexto de Ortopedia y Traumatología entre preceptores insertos en una Residencia Multidisciplinar en Salud en Atención Integral de Traumatología y Ortopedia. Se trata de un estudio cuantitativo, descriptivo y transversal de 29 preceptores mediante la aplicación de una encuesta realizada por los autores. Los datos se procesaron en Microsoft Excel Office 2013 y la prueba de chi-cuadrado en BioEstat 5.3 con $p=0.05$. Los resultados $72,4 \%, n=21$ respondieron "No" cuando se le preguntó si tuvieran acceso al Proyecto Político Pedagógico (PPP) y la proporción de $93,1 \%, n=27$ creen que la residencia se enfrenta el 
fortalecimiento de los principios y directrices del SUS. Por lo tanto, el proceso de enseñanza y aprendizaje de la Multidisciplinar residencia tiene buenos puntos, así como algunas lagunas en su estructura que pueden minimizarse mediante la organización y la integración entre el personal involucrado en el programa, para que la enseñanza y el aprendizaje sean un instrumento de cambio en el suministro de atención médica de calidad a la comunidad.

Palabras clave: Residencia. Multiprofesional. Preceptores.

\section{INTRODUÇÃO}

Segundo Mendes et al (2011, p. 01), o Sistema Único de Saúde (SUS) requer um perfil diferenciado dos atores pertencentes ao cenário da atenção em saúde, tendo em vista os princípios "da universalidade, integralidade, equidade, intersetorialidade, humanização do atendimento e participação social", o que significa dizer que o SUS tem forçado uma reformulação da atuação da equipe de saúde de forma que seja garantido um atendimento multiprofissional na assistência ao usuário.

Para a efetivação desta proposta o SUS assumiu, entre suas atribuições, a responsabilidade por qualificar os recursos humanos e isso materializa-se através da criação dos programas de Residências Multiprofissionais em Saúde, por meio da parceria entre o Ministério da Saúde e Ministério da Educação para que o ensino em saúde seja voltado para a concretização dos princípios e diretrizes do SUS (GUIMARÃES, 2010).

Dentre as Residências Multiprofissionais presentes no Brasil está a Residência Multiprofissional em Saúde, na área de Atenção Integral em Ortopedia e Traumatologia, implantada no Hospital Regional do Baixo Amazonas (HRBA) em Santarém, no interior do Estado do Pará, em março de 2013, incluindo vagas para Fisioterapeutas, Terapeutas Ocupacionais, Enfermeiros, Psicólogos, Assistentes Sociais e Farmacêuticos através de uma parceria entre a Universidade do Estado do Pará (UEPA) e o Hospital Regional do Baixo Amazonas (HRBA).

Um dos desafios encontrados nas residências diz respeito ao desenvolvimento dos recursos pedagógicos utilizados no processo de ensino aprendizagem. Nesse contexto, Share (2012) aponta os preceptores como um dos atores principais e cita a necessidade destes possuírem preparo 
pedagógico para lidar com tais recursos e promoverem, através do diálogo, a reflexão crítica a respeito da realidade, para obterem bom nível de aproveitamento no processo de ensino aprendizagem.

Diante do exposto, buscou-se compreender a percepção sobre o processo de ensino aprendizagem entre preceptores da Residência Multiprofissional em Saúde de Atenção Integral em Traumatologia e Ortopedia. E assim, identificar o interesse dos preceptores quanto a alguns aspectos de sua própria formação e atuação enquanto preceptor, e ainda, verificar a opinião destes a respeito do Projeto Político Pedagógico (PPP) e o currículo em Ortopedia e Traumatologia desenvolvido na Residência.

Esta pesquisa foi estruturada a partir dos seguintes pontos: descrição da metodologia empregada no estudo, resultados e discussão acerca dos achados quantitativos e, por fim, a conclusão.

\section{METODOLOGIA}

Trata-se de um estudo quantitativo, descritivo e transversal desenvolvido no Hospital Regional do Baixo Amazonas Dr. Waldemar Penna (HRBA) detentor do título de Hospital Escola (ES) e pioneiro na implantação do programa de Residência Multiprofissional na Atenção Integral em Traumatologia e Ortopedia no município de Santarém - PA. Este programa possui o compromisso de desenvolver a formação profissional capaz de aplicar os princípios e diretrizes do SUS na prática integralizada da assistência multiprofissional de saúde nos diferentes estágios de complexidade a partir das necessidades da região.

Os acometimentos ortopédicos e traumatológicos correspondem a uma das principais demandas regionais atendidas no HE que conta com a parceria da Residência em questão na assistência ao usuário. Nesse contexto, a percepção dos preceptores atuantes nessa área a respeito do ensino e aprendizagem é de grande valia, pois estão diariamente envolvidos na teoria e prática da formação profissional juntamente com os residentes e equipe de gestão do programa. 
O presente estudo contou com a participação de 29 preceptores, pertencentes ao programa de Residência Multiprofissional na Atenção Integral em Traumatologia e Ortopedia, que assinaram $\circ$ Termo de Consentimento Livre e Esclarecido (TCLE) e responderam a um questionário contendo 11 questões fechadas a respeito do processo de ensino aprendizagem desenvolvido no programa.

Para a análise dos dados foi utilizado o programa Microsoft Excel Office 2013 (Windows), onde foram tabulados através de frequência absoluta e relativa, e ainda o aplicativo Bioestat 5.0, no qual foi definido um nível de significância de $5 \%(p<0,05)$ e os intervalos de confiança construídos com $95 \%$ de confiança estatística. A pesquisa foi submetida à avaliação pelo Comitê de Ética em Pesquisa da Universidade do Estado do Pará (Campus XII - Santarém) e obteve aprovação através do CAAE nº 1582.811.

\section{RESULTADOS E DISCUSSÃO}

A seguir, estão descritos os resultados obtidos e as discussões pertinentes para cada questionamento:

TABELA 01 - Características gerais da amostra

\begin{tabular}{cccc}
\hline Características da amostra & Amostra $(\mathbf{n = 2 9})$ & $\%$ & $\mathbf{P}$ \\
\hline Gênero & & & \\
Feminino & 20 & $69,0 \%$ & $0,0411^{*}$ \\
Masculino & 09 & $31,0 \%$ & \\
\hline Faixa-etária & & & \\
De 24 a 30 anos & 14 & $48,3 \%$ & 0,0656 \\
De 31 a 40 anos & 11 & $37,9 \%$ & \\
De 41 a 46 anos & 04 & $13,8 \%$ & \\
\hline
\end{tabular}

Fonte: os autores

Com relação às características da amostra, a tabela 1 revela que a maioria (69,0\%; $n=20)$ dos preceptores são do sexo feminino e estão em sua maioria entre a faixa etária de 24 a 30 anos. 
TABELA 02: Percepção sobre $\bigcirc$ processo de ensino aprendizagem desenvolvido no contexto da Ortopedia e Traumatologia entre preceptores

Questōes Amostra $(\mathbf{n}=29) \quad \% \quad P$

Você teve acesso ao Projeto Político Pedagógico (PPP) utilizado como dispositivo legal aplicado ao Programa da Residência Multiprofissional?

$\begin{array}{llll}\text { Sim } & 08 & 27,6 \% & 0,0158^{*} \\ \text { Não } & 21 & 72,4 \% & \end{array}$

Você concorda que a Residência Multiprofissional em Ortopedia e Traumatologia está de acordo com as normas do PPP?
Sim
12
$41,4 \%$
0,3532
Não
17
$58,6 \%$

Você possui em sua formação profissional algum curso didático-pedagógico voltado para preceptoria ou experiência em docência?

$\begin{array}{lll}\text { Sim } & 14 & 48,3 \% \\ \text { Não } & 15 & 51,7 \%\end{array}$

0,8527

Em relação à Ortopedia e Traumatologia, com que frequência você mais se atualiza acerca desse tema?

$\begin{array}{lll}\text { Semanalmente } & 14 & 48,3 \% \\ \text { Mensalmente } & 07 & 24,2 \% \\ \text { Semestralmente } & 05 & 17,2 \% \\ \text { Não me atualizo } & 03 & 10,3 \%\end{array}$

Como você classifica, o seu autoconhecimento em Ortopedia e Traumatologia, de 1 a 5 pontos (sendo 1 a menor nota e 5 a maior)?

$\begin{array}{lll}1 & 02 & 06,9 \% \\ 2 & 04 & 13,8 \% \\ 3 & 11 & 37,9 \% \\ 4 & 08 & 27,6 \% \\ 5 & 04 & 13,8 \%\end{array}$

Você tem conhecimento a respeito das metodologias ativas de ensino?

\begin{tabular}{llll} 
Sim & 21 & $72,4 \%$ & $0,0158^{*}$ \\
Não & 08 & $27,6 \%$ & \\
\hline
\end{tabular}

No processo de ensino aprendizagem da Ortopedia e Traumatologia, você aplica as metodologias ativas?
Sim
20
$69,0 \%$
$0,0411^{*}$
Não
09
$31,0 \%$

São realizadas reuniões em períodos regulares entre tutores e preceptores para a discussão e organização do currículo da Ortopedia e Traumatologia?

$\begin{array}{llll}\text { Sim } & 07 & 24,1 \% & 0,2270 \\ \text { Não } & 14 & 48,3 \% & \\ \text { Não sei } & 08 & 27,6 \% & \end{array}$

A partir do currículo proposto no Programa, quão importante você julga ser a disciplina Ética/Bioética no contexto da Ortopedia e Traumatologia? (1 a 5)

$\begin{array}{llll}1 & 02 & 06,9 \% & <0,0001^{*} \\ 2 & 01 & 03,4 \% & \\ 3 & 00 & 00,0 \% \\ 4 & 06 & 20,7 \% & \end{array}$




\begin{tabular}{|c|c|c|c|}
\hline \multicolumn{4}{|c|}{$\begin{array}{l}\text { Uma vez que a Residência em Ortopedia e Traumatologia possui caráter multiprofissional, } \\
\text { você consegue observar a aplicação conjunta da multidisciplinaridade e } \\
\text { interdisciplinaridade nas discussões dos casos clínicos? }\end{array}$} \\
\hline Sim & 13 & $44,8 \%$ & \multirow[t]{2}{*}{$0,0302^{*}$} \\
\hline Não & 09 & $31,0 \%$ & \\
\hline Somente interdisciplinaridade & 03 & $10,4 \%$ & \\
\hline Somente multidisciplinaridade & 04 & $13,8 \%$ & \\
\hline \multicolumn{4}{|c|}{$\begin{array}{l}\text { Em sua opinião, você acredita que a Residência está voltada para o fortalecimento dos } \\
\text { princípios e diretrizes do SUS? }\end{array}$} \\
\hline $\operatorname{Sim}$ & 27 & $93,1 \%$ & $<0,0001^{*}$ \\
\hline Não & 02 & $06,9 \%$ & \\
\hline
\end{tabular}

Fonte: os autores

Na Questão 1, a maioria dos participantes $(72,4 \%$; $n=21)$ respondeu "Não" quando questionados se tiveram acesso ao Projeto Político Pedagógico (PPP) utilizado no programa. Nessa questão era esperado que os preceptores tivessem acesso ao PPP para conhecerem, em detalhes, aspectos do processo de ensino e aprendizagem. A não participação dos preceptores na construção do PPP é confirmada através da pesquisa de Galvão (2017), realizada com este mesmo grupo, em que a maioria dos preceptores entrevistados (95\%) afirma que não participaram da formulação deste. Em relação à estrutura organizacional do PPP da Residência Multiprofissional na Atenção Integral em Ortopedia e Traumatologia do presente estudo, Galvão (2017) ressalta que:

\footnotetext{
Pela estrutura delineada, este documento, que é considerado o PPP do programa da Residência, se apresenta de forma concisa, demonstrando uma visão ampliada das atividades a serem desenvolvidas, sem, contudo, evidenciar o perfil de residentes multiprofissionais em Ortopedia e Traumatologia que se deseja formar, embora apresente o perfil do egresso e as habilidades que cada área deve adquirir no decorrer do curso, sendo que, a parte específica da formação está apresentada de forma generalizada (GALVÃO, 2017).
}

A participação dos preceptores na construção do PPP representaria um meio de terem acesso a tal documento e ainda lhes daria a possibilidade de opinar nas normas contidas nesse dispositivo pedagógico.

Para Veiga (2007), a construção do PPP deve ser algo articulado a partir de um processo democrático de decisões entre todos os envolvidos 
nas atividades pedagógicas, onde a preocupação também deve estar voltada para um trabalho organizado, que vença os conflitos interpessoais como a competitividade e alcance a diminuição da hierarquização no processo das tomadas de decisões. A autora ainda acrescenta que o PPP deve ser um documento planejado e vivenciado pelas pessoas atuantes no processo educativo, pois este não corresponde a um mero conjunto de planos e atividades a serem simplesmente arquivados ou repassados para servirem como comprovantes da realização dos afazeres burocráticos.

Diante dos resultados encontrados na questão 1 e a partir da discussão dos autores citados, podemos incentivar a formação de uma gestão participativa como elemento basilar para a construção do PPP.

Para Medeiros et al (2010) a gestão participativa entre os profissionais da saúde é uma forma de descentralizar o processo de decisão e ação, pois todos passam a compartilhar as responsabilidades e, assim, abre espaço para uma cogestão na qual a criatividade e autonomia de cada profissional são valorizadas no trabalho em equipe, em prol da oferta de melhor serviço em saúde. Freire (2005) cita que é importante o indivíduo entender o contexto em que está inserido e ainda sentir-se capaz de participar ativamente das mudanças propostas.

$\mathrm{Na}$ Questão 3, quando indagados se possuem na formação profissional algum curso didático-pedagógico voltado para preceptoria ou experiência em docência, $51,7 \%(n=15)$ dos preceptores marcaram a opção "Não". Referente a cursos didático-pedagógicos, Cantani e Jeneral (2016) afirmam que os preceptores devem buscar conhecimentos para qualificar sua formação e auxiliar o residente para que consigam suprir as demandas em saúde apresentadas pelos usuários.

A oferta de cursos para a formação pedagógica voltada para preceptores é algo recomendado por Galvão (2017) ao perceber a carência desse tipo de iniciativa na Residência, por meio do presente estudo. 
Para Rocha e Ribeiro (2012), o preceptor possui papel fundamental na formação dos alunos, uma vez que está presente no momento em que a teoria é aplicada à prática clínica. Esta prática é moldada e revelada através dos conhecimentos específicos de cada profissão durante as atividades do dia-a-dia, além disso, o preceptor é tido como uma referência para os alunos. Os autores citam a formação pedagógica como elemento importante para que os preceptores tenham domínio tanto dos métodos quanto das técnicas inclusas no processo de ensino aprendizagem.

Longhi (2014) traz em sua abordagem a discussão acerca das Diretrizes Curriculares Nacionais (DCN) dentro do contexto da formação pedagógica na preceptoria. Para o autor, as DCN reforçam a necessidade de orientar a formação profissional baseada em aspectos como a humanização e integralidade, para que os profissionais ofereçam melhor qualidade de assistência em saúde levando em consideração as demandas sociais da população.

Para que a formação dos preceptores esteja de acordo com as DCN, Rocha; Ribeiro (2012) apontam a iniciativa das instituições gestoras como elemento chave nesse processo:

Contudo, de pouco adianta haver diretrizes se os responsáveis pela formação dos futuros profissionais não estiverem cientes e conhecedores desses norteadores, bem como determinados a atingi-los. Nesse aspecto, cabe às instituições tomar para si a responsabilidade de preparar esses formadores, criando, por meio da gestão, políticas que definam formação, avaliação e monitoramento do preceptor, possibilitando atender os requisitos das DCN (ROCHA; RIBEIRO, 2012, p.346).

Além de cursos didáticos pedagógicos voltados para a preceptoria, os preceptores também precisam estar atualizados a respeito das novas evidencias científicas em Traumatologia e Ortopedia, uma vez que, segundo Freire (2005), os saberes estão em constante mudança e torna-se necessário que os atores desse processo se atualizem para renovar seus conhecimentos e compartilhá-los na participação ativa da construção dos saberes. 
Nessa perspectiva, a quarta questão mostra que uma parcela significativa dos participantes $(48,3 \% ; n=14)$ respondeu que se atualiza "Semanalmente" acerca do tema Ortopedia e Traumatologia. Porém, ao relacionar tal achado com o resultado da questão 5 na qual a maioria dos preceptores (37,9\%; $n=11$ ) atribuiu "Nota 3" referente a classificação do autoconhecimento em Ortopedia e Traumatologia, nota-se uma contradição de informações entre as questões, pois teoricamente o esperado é que a frequência semanal de atualização traga níveis elevados de conhecimento, mas no presente estudo é observado justamente o oposto do esperado a partir do resultado da questão 4.

Abrindo uma discussão pertinente e relacionada aos resultados da questão 4 e 5, Ceccim (2005) analisa que a renovação em alta velocidade de conhecimentos, tecnologias a serviço da área da saúde e a demanda de distribuição de trabalhadores e serviços de forma acessivel à população, configura a atualização permanente dos profissionais de saúde de forma bastante complexa. Torna-se crucial o desenvolvimento de recursos tecnológicos de operação do trabalho perfilados pela noção de aprender a aprender, de trabalhar em equipe, de construir cotidianos eles mesmos como objeto de aprendizagem individual, coletiva e institucional (CECCIM, 2005).

Para o autor, a divisão discrepante de profissionais em grandes concentrações nos centros de maior desenvolvimento, a predominância da formação hospitalar impregnada de preceitos tecnológicos e biológicos do cuidado são realidades que requerem ações ousadas na evolução da formação dos profissionais de saúde, onde o enfoque está em priorizar o trabalho multiprofissional em ações coletivas entre as equipes, com intuito de alcançar resolutividade dos dilemas em saúde da população atendida. Caso contrário, se a metamorfose na formação dos profissionais não ocorrer, a qualidade do serviço será colocada em risco pela desatualização e déficit de domínio de saberes necessários para as diferentes situações e níveis de complexidade. 
Quando Ceccim (2005) discorre sobre situações complexas a serem enfrentadas, ele faz referência à existência dos saberes tradicionais de diferentes culturas e atribuições de sentidos ao processo "saúde-doençacuidado-qualidade de vida" que se diferenciam dos moldes racionais do cientificismo contido nas práticas dos trabalhadores da saúde, mas que devem ser considerados para que as metas terapêuticas sejam alcançadas. Essa percepção se enquadra na realidade da população atendida pela Residência do estudo, pois o saber tradicional é uma característica forte na cultura do povo da região do Baixo Amazonas.

Os resultados das questões 4 e 5 e a opinião de Ceccim (2005) corroboram quanto a necessidade da implementação da Educação Permanente em Saúde (EPS) para a abertura de um campo de discussões em torno do serviço de Traumatologia e Ortopedia no contexto do espaço hospitalar, da população atendida e de acordo com o SUS.

Segundo Davini (2009, p. 58), a Educação Permanente em Saúde (EPS), é "a educação no trabalho, pelo trabalho, e para o trabalho nos diferentes serviços, cuja finalidade é melhorar a saúde da população". Luz (2010) corrobora com Davini (2009) ao afirmar que a EPS é um meio de garantir capacitação no próprio ambiente de trabalho, onde todos os profissionais têm a oportunidade de participar e de interagir uns com os outros em um processo de ensino e aprendizagem que nasce a partir das vivências cotidianas dos profissionais de saúde.

A EPS, segundo Saupe (2008), é baseada na aprendizagem significativa. Partindo dessa afirmação, Ezequiel (2012) cita o método da problematização como instrumento pedagógico utilizado na EPS e concorda com Berbel (1998), que na problematização existem diferentes etapas relacionadas entre si de acordo com um dilema pertencente à realidade. E ainda dizem mais, a problematização permite ao ser humano tomar consciência da sua realidade para que, assim, torne-se um ator ativo na construção de mudanças positivas em defesa e luta pela dignidade humana. 
Saupe (2008) corrobora com Ezequiel (2012) e Berbel (1998) no momento em que acreditam no poder da problematização aplicada na EPS para analisar o processo de trabalho, identificar os dilemas existentes neste para que, assim, possa transformar as práticas profissionais, fortalecer 0 trabalho em equipe e modificar a realidade em saúde que os cerca, de acordo com as necessidades da população. Para Lopes (2007), a EPS traz consigo o poder de ruptura do modelo hospitalocêntrico enraizado nas ciências médicas.

Ceccim (2005) revela que a implantação e implementação da EPS perpassam pelo quadrilátero da formação, caracterizada pelas seguintes análises: análise da educação dos profissionais de saúde, análise das práticas de atenção à saúde, análise da gestão setorial e análise da organização social. De acordo com o autor, a EPS deve estar constantemente reformulando-se a partir das discussões sobre a atuação no cotidiano do trabalho:

\begin{abstract}
Tomar o cotidiano como lugar aberto à revisão permanente e gerar o desconforto com os lugares "como estão/como são", deixar o conforto com as cenas "como estavam/como eram" e abrir os serviços como lugares de produção de subjetividade, tomar as relações como produção, como lugar de problematização, como abertura para a produção e não. A EPS traz em sua didática as metodologias ativas de ensino como um novo caminho cada vez mais conhecido e percorrido no ensino em saúde (CECCIM, 2005).
\end{abstract}

A nível local, $72,4 \%$ ( $n=21$ ) dos preceptores afirmam ter conhecimento a respeito das metodologias ativas de ensino frente a $27,6 \%(n=8)$ que desconhecem a respeito destas. O ideal seria a readequação do PPP para que possa apresentar, mais claramente, as metodologias ativas como princípio da prática pedagógica do curso, explicitando o que são, para que servem e qual ou quais tipos de metodologias ativas devem ser utilizadas na residência, além de promover aos preceptores o acesso a tal documento, pois na questão 1, em sua maioria, afirmaram não ter contato com este.

Além da maioria ter conhecimento a respeito das metodologias de ensino como constatado na Questão 6, a maioria dos participantes $(69,0 \%$; 
n=20) realiza a aplicabilidade destas no contexto da Ortopedia e Traumatologia. Tal fato corrobora com a pesquisa de Honda e Chierli (2015) onde os preceptores da Residência Multiprofissional em Saúde (RMS) da Faculdade de Medicina de Marília (FANEMA) também desenvolvem o processo de ensino aprendizagem baseado nas metodologias ativas de ensino na busca da resolução de problemas cotidianos, aproximando a teoria com a prática.

Vale ressaltar que as metodologias ativas, segundo Berbel (2011), possuem caminhos metodológicos que problematizam a realidade para que, assim, possa transformá-la a partir da discussão entre professores e alunos em um processo ativo de construção do conhecimento através dos saberes empíricos e científicos no ato do compartilhamento de informações.

Embasando os achados de Honda e Chierli (2015), Berbel (2010) discorre sobre o despertar da curiosidade dos alunos quando entram em contato com as metodologias ativas na formação em saúde na medida em que descobrem, nas teorizações, elementos até então desconhecidos por eles próprios e por seus professores, onde através de discussões passam a ter seus conhecimentos valorizados e, assim, estimulados quanto ao sentimento de engajamento. Para Marin et al (2009), as metodologias ativas direcionam a formação profissional para além da técnica, abrangendo principalmente os aspectos biopsicossociais do processo saúde-doença, presentes em uma sociedade constituída a partir das raízes hospitalocêntricas.

Berbel (2010) destaca a possibilidade das metodologias ativas apresentarem condições de liberdade e autonomia aos alunos. Neste sentido, corrobora com Paulo Freire (2005) e Muttri et al (2008), pois acreditam que o gerador de impulso para o aprendizado é a teoria associada a prática do cotidiano, no tocante a superação de situações reais debatidas que dispertem o senso crítico na construção de novos saberes a partir de suas experiências. Nesse sentido, as atuações estariam contextualizadas, com possibilidade de minimizar as situações de injustiça e desigualdade, promovendo e garantindo o direito a qualidade de vida aos 
usuários do serviço de saúde, de acordo com os princípios que regem a saúde pública, representada e legitimada através do Sistema único de Saúde (SUS), como fruto da Reforma Sanitária.

Como sugestão, a Pedagogia Histórico-crítica, criada por Dermeval Saviani, poderá nortear os métodos ativos que precisam ser melhor descritos no PPP da residência do presente estudo.

Segundo Moreira (2014), é importante entender a pedagogia histórico-crítica e sua consolidação a partir da história da educação no Brasil. O autor corrobora com Saviani (2003) ao afirmar que a educação passou por uma espécie de evolução histórica que vai desde a pedagogia católica instaurada pelos jesuítas, passando pelas teorias não-críticas e críticas-construtivistas até chegar na pedagogia histórico-crítica em 1980 , defendida por pensadores como Freire (2005) que a interpreta, segundo Libâneo (1986), a partir da ótica "progressista libertadora".

Mashiba e Menezes (2012) acrescentam que a história da educação perpassa os conflitos históricos sociais que se afloraram desde a exploração feudal e consolidação do sistema capitalista, como modo de produção de exploração, no qual o homem era concebido como parte da engrenagem de uma máquina, onde desempenhava seu papel sem se opor e tolido da percepção do próprio processo de trabalho, isto é, o indivíduo torna-se uma peça desumanizada.

Para Mashiba e Menezes (2012) a educação era vista como mero instrumento ideológico de controle por parte do estado brasileiro. Saviani (2005) acrescenta que isso era nítido no Regime Militar brasileiro e nesse momento existiu a necessidade de superar tanto as pedagogias não-críticas (concepção tradicional, escolanovista e tecnicista) quanto as críticoreprodutivistas. Segundo o autor, surge a Pedagogia Histótico-Crítica, com perspectiva historicizadora, propondo uma ótica contra-hegemônica.

Para Saviani (2014) a pedagogia histórico-crítica possui o poder de transformar a sociedade capitalista a partir de sua base enraizada no materialismo histórico dialético marxista. Na prática educativa, Gasparin e 
Petenunci (2009) nos mostram de forma didática a pedagogia históricocrítica através de cinco passos: prática social, problematização, instrumentalização, catarse e prática social.

A incorporação das metodologias ativas e da pedagogia históricocrítica são elementos propostos pelos autores deste estudo como pauta de discussão entre os tutores e preceptores no que tange a estrutura do currículo existente na Residência. Para isso, é louvável a realização de reuniões conjuntas e regulares entre estes para a organização do currículo da Ortopedia e Traumatologia, visto que esses encontros não são frequentes como apontado pela maioria dos preceptores $(48,3 \% ; n=14)$.

Barros (2010) conclui em seu estudo que no delineamento curricular as atividades devem ser estruturadas e desenvolvidas de forma sistematizada, no qual as disciplinas ou módulos são desenvolvidas de forma harmônica, no que diz respeito à integração entre teoria e prática, contextualizando-as de acordo com os elementos socioculturais e políticos da região a ser atendidas. Para o autor, no currículo deve constar também os processos avaliativos, tanto do curso quanto dos alunos, os temas e a metodologia utilizada.

Dentre as disciplinas ministradas no programa estão a Ética e Bioética, ofertadas sob a forma de eixo comum a todos os residentes. Segundo a opinião da maioria dos preceptores $(69,0 \% ; n=20)$, estas disciplinas são de suma importância no currículo proposto pelo Programa da Residência.

O resultado da pesquisa em questão vai ao encontro dos achados de Alexandre (2013), em seu estudo acerca da importância do ensino da Ética e Bioética na Residência Médica a maioria dos preceptores (100\%; $n=6$ ) considera importante a inclusão da temática no currículo e na prática do cotidiano. Na pesquisa, o autor mostra que a bioética, para os entrevistados, significa um instrumento de auxílio na postura do profissional diante dos dilemas encontrados na assistência e nas pesquisas, e deve ser um tema sempre debatido entre preceptores e residentes no processo educacional. 
A ética, enquanto disciplina na área da saúde, deve proporcionar o debate frente às novas técnicas científicas que surgem com o progresso da ciência (GOMES, 2009) e a responsabilidade do pesquisador diante do conhecimento produzido, seu compromisso social e político com o avanço da ciência e da tecnologia.

No tocante a assistência ao usuário de saúde, Haddad e Zoboli (2010) concordam que o estudo da bioética permite, ao profissional da saúde, olhar o paciente como um todo complexo pertencente a um contexto biopsicossocial e interpretá-lo como detentor do direito ao atendimento humanizado, pautado numa perspectiva de totalidade diferentemente da vertente cartesiana da separação corpo e mente.

Em sua análise, Ramos et al (2013) considera a importância da reflexão ética e bioética além do quesito profissional ao considerá-la como ponto de partida para o autoconhecimento, pois o modo de ser de cada um exerce influência nas próprias atitudes e nas relações interpessoais. Em sua reflexão, Ramos et al (2013) concorda com o filósofo Foucault (2006) que reforça a necessidade de transformação do ser humano através de um trabalho ético sobre si, visto que o sujeito moral construído dentro de cada um reflete em suas escolhas.

Na realidade local, poucos estudos abordam a ética e bioética na saúde, temos como exemplo o estudo de Magalhães et al (2016), que também trata sobre a temática ética na opinião de professores fisioterapeutas, o estudo obteve resultado satisfatório, pois a maioria dos entrevistados (78\%; $n=14$ ) atribuiu Nota 5 , em uma escala de 0 a 5 , ao nível de importância da disciplina no currículo da graduação.

Ao observar o currículo proposto pelo Programa da Residência Multiprofissional, abordada no presente estudo, percebe-se a ausência da disciplina de Antropologia da Saúde na grade curricular. Sabemos que uma das habilidades requeridas pelo SUS é a capacidade de lidar com diferentes situações e pessoas com diferentes percepções a respeito do processo de saúde e doença. Para Soares (2001), 
Diversas formas de se relacionar com as doenças e práticas de cura atravessam a história do Brasil, desde a chegada dos colonizadores portugueses até a atualidade. Os vários modos de lidar com as enfermidades presentes no Brasil têm uma longa história, pois "índios, africanos e portugueses das camadas populares, assim como alguns membros das elites, sempre haviam, em suas regiões de origem, recorrido às mezinhas e ao mundo dos mortos para curar suas enfermidades muito antes de se cogitar a colonização do Brasil" (p. 422).

Segundo Santos et al (2012), a disciplina de antropologia da saúde permite entender não somente as diferentes visões e modos de lidar com as enfermidades, mas proporciona também, dentre outras discussões, o entendimento acerca das relações entre a medicina científica e as práticas populares desenvolvidas em comunidades tradicionais.

Na região amazônica a presença de práticas populares na área da saúde é algo expressivo na cultura desse lugar. Para Santos et al (2012), as práticas populares de curandeiros, feiticeiros e benzedeiras resistem até os dias atuais frente ao ideal positivista, que alguns profissionais da saúde reproduzem ao discriminarem e imporem o cientificismo fechado em suas ações cotidianas, seja por falta de formação, por conta dos procedimentos próprios dos serviços de saúde ou, ainda, pelo descaso com o sofrimento e a dor do usuário de saúde, acabam por dissociar as questões históricas, culturais e sociais do processo de saúde e doença vivenciado pelos usuários.

Abordando sobre a questão cultural, Yajahuanca (2015) destaca que os diferentes grupos sociais possuem um olhar sobre 0 sofrimento, as perturbações físicas, espirituais, mentais etc., de acordo com suas concepções. Para o autor, a interculturalidade corresponde a relação respeitosa e compreensiva na maneira de etender a realidade do outro, incorporando no caso da saúde, a cultura do usuário durante o cuidado prestado a ele ao considerar os saberes locais e tradicionais, estabelecendo uma linguagem acessível no cuidado pautado no respeito e longe do etnocentrismo e discriminação.

Tendo em vista que a Residência Multiprofissional, foco deste estudo, está em um hospital que atende populações tradicionais que trazem 
consigo aspectos peculiares de sua cultura amazônida, repleta de saberes e práticas tradicionais, é de suma importância conhecer o contexto cultural da comunidade. E isto pode ser fomentado através da disciplina de Antropologia da Saúde, que conforme Santos et al (2012) discute o processo saúde e doença, a cultura, a sociedade e reflete criticamente as políticas públicas em saúde, apresentando alternativas para qualificá-la, contribuindo, assim, no serviço em saúde.

$\mathrm{Na}$ décima questão, a maioria dos preceptores $(44,8 \% ; n=13)$ respondeu "Sim" quando interrogados se no contexto da Residência em Ortopedia e Traumatologia conseguem observar a aplicação conjunta da multidisciplinaridade e interdisciplinaridade nas discussões de casos clínicos.

Segundo Santos et al (2007), a multidisciplinaridade é a interrelação entre várias disciplinas, onde cada uma revela a sua visão a respeito de determinado assunto; uma determinada questão é discutida de maneiras diferentes de acordo com cada disciplina. Já a interdisciplinaridade, para o autor, materializa-se na troca de conhecimentos entre variadas disciplinas, ou seja, diferentes visões acerca de um caso se organizam e se intercruzam para a produção de novos saberes para o melhor entendimento do mesmo.

Para Bispo, Tavares e Tomaz (2014) as DCN preconizam que a formação em saúde deve contemplar o SUS através do trabalho em equipe na oferta de atenção integral a saúde em oposição à prática fragmentada, individualista e desarticulada entre os profissionais da saúde. Para os autores, a integralidade da atenção orientada pelo SUS pode ser alcançada a partir da prática interdisciplinar, detentora de um olhar ampliado, que perpassa o tecnicismo e cientificismo, ao estimular a importância da coletividade na simbiose de diferentes categorias profissionais que juntas constroem, de forma integrada, um novo saber.

Fonseca e Rocha (2012), afirmam que o modelo biomédico e hospitalização da saúde, instituída ao longo da historia, formam uma barreira para a integralidade da atenção à saúde e, nesse contexto, a 
interdisciplinaridade surge como um movimento de crítica e oposição ao modelo biomédico enraizado no sistema de saúde.

Para Foucault (2001), o hospital medicalizado advém da associação entre disciplinarização desse espaço e a presença constante do médico no ambiente hospitalar. Segundo Filho (2004), à medida que os médicos assumiram e centralizaram o controle das ações em saúde, estes adquiriram mais influência e passaram a se impor sobre a sociedade como o serviço mais importante e essencial frente às demais profissões que exercem, de forma subalterna, sua força de trabalho com enfoque apenas nos procedimentos baseados nas ordens médicas. Isso acarretou a falta de parceria entre os profissionais desarticulando a interdisciplinaridade e reforçando a visão hierarquizada dos atores desse processo em ações técnicos-curativistas e menosprezando a articulação dos diferentes níveis de atenção.

Assim, a ênfase nos aspectos biológicos para interpretação dos fenômenos vitais, nos procedimentos, no saber médico e nas especialidades denotam a influência que sofrem os processos de trabalho. Esse modelo é organizado a partir de uma divisão de tarefas entre seus agentes, sendo o médico o centro dessa assistência (MARQUES; LIMA, 2008).

Outro fator limitante para interdisciplinaridade advém de um processo histórico. O modo de produção capitalista na figura do taylorismo/ fordismo no período da Revolução Industrial, segundo Santomé (1998), também afetaram os sistemas educacionais dificultando a interdisciplinaridade no momento em que organizaram as disciplinas de forma isoladas uma das outras, no bojo de um currículo descontextualizado com a realidade, gerando a fragmentação do saber, pautando a educação na mera repetição e memorização de conhecimentos. Cohen (2012) e Tenorio (2011) afirmam que a organização do processo de trabalho em saúde reproduz o modelo Taylorista por meio da fragmentação do trabalho e coisificação do ser humano e, em consenso com a visão fordista, traz a especialização do 
trabalho, onde cada trabalhador exerce determinada função no processo de produção.

Gelbcke, Matos e Sallun (2012) afirmam que uma forma de incentivo a multidisciplinaridade $e$ interdisciplinaridade no processo de ensino e aprendizagem corresponde à oferta de disciplinas de forma conjunta, para mais de uma categoria profissional, com objetivo de estabelecer o diálogo entre todos. Além disso, estabelecer um elo entre as disciplinas para criar a relação de transversalidade nos módulos estudados.

As disciplinas isoladamente não dão conta de produzir as respostas necessárias a um mundo que é composto de uma multiplicidade de fatores que não são mutuamente excludentes e sim explicados uns em relação aos outros. O mundo não é feito de coisas isoladas, existe uma complementariedade de dimensões. A compreensão desse mundo exige uma visão da realidade que transcenda os limites disciplinares (FEUERWERKER; SENA, 1999).

Na Questão 11, a maioria dos entrevistados $(93,1 \% ; n=27)$ respondeu "Sim" quando questionados se acreditam que a Residência está voltada para o fortalecimento dos princípios e diretrizes do SUS. Além do resultado positivo corresponder um avanço por parte da Residência em relação ao atendimento em saúde, a constatação encontrada reforça a ideia da Residência cumprir seu dever social na contribuição da efetivação de um sistema enraizado num processo de resistência política, ao longo da história brasileira.

Os autores Bertolli-filho (2003) e Brasil (2006) fazem uma retrospectiva histórica em suas pesquisas e revelam a consolidação do SUS e a criação de seus princípios e diretrizes como frutos de lutas sociais no decorrer da história da saúde pública no Brasil, na qual a participação da sociedade civil foi crucial no combate aos interesses capitalistas que pretendiam mercantilizar a saúde. Diante disso, é importante contextualizar historicamente a criação do SUS para disseminar o ideal de valorização e perpetuação desse sistema. 
Bertolli-filho (2003) aborda a historia da saúde Pública no Brasil afirmando que esta passa por vários momentos marcantes, sendo eles:

Chegada da Família Real no Brasil (1808): a partir da comercialização entre navios e, consequente, disseminação de determinadas doenças nesse período, foi desenvolvida no Brasil uma estrutura sanitária mínima que protegeu não somente a saúde da família real como também prezou pela saúde dos trabalhadores envolvidos nesse processo, uma vez que estes últimos precisavam estar saudáveis como mão-de-obra barata satisfazer os interesses econômicos da corte portuguesa, pois esta precisava manter a produtividade e lucro advindos da comercialização.

Proclamação da república (Sanitarismo Campanhista): nesse momento, o Brasil é organizado em um sistema tipicamente capitalista através de uma economia agroexportadora e controle politico nas mãos de grandes latifundiários, ou seja, o país era refém dos capitalistas agrários. Sem um modelo sanitário estabelecido, as cidades estavam vulneráveis as epidemias e uma delas se deu pela disseminação da varíola, que foi combatida através da iniciativa de Oswaldo Cruz em parceria com o estado.

Vale ressaltar que a vacinação obrigatória ocorreu de forma truculenta e repressiva, já que a prioridade da elite não era promover saúde pública para o bem-estar, mas ter uma classe proletária saudável para manter a máquina capitalista funcionando. Como consequência, uma grande parte da população se opôs a tal prática, ficando este movimento conhecido por "Revolta da Vacina" e, assim, forma-se o modelo de saúde da época chamado Sanitarismo Campanhista, de caráter preventista, autoritário e antidemocrático.

Governo de Getúlio Vargas (1930 a 1945) e Ditadura Militar (1964): durante o governo de Getúlio Vargas os marcos importantes relacionado à saúde pública é a criação do Ministério da Saúde e Ministério da Educação e Saúde Publica. No contexto de repressão da ditadura militar o governo da época se eximiu do dever de prover saúde enquanto estado e lançou tal 
responsabilidade nas mãos da iniciativa privada. Nesse momento foram criados órgãos da Previdência Social a partir dos quais somente uma parcela da população (elite) tinha acesso à saúde, pois a grande massa (proletariado), desprovida de condição monetária, não tinha como financiar tal serviço. Na tentativa de minimizar a situação a filantropia, materializada pela figura da igreja, atuou através das Santas Casas de Misericórdia para dar suporte em saúde para os menos favorecidos.

Nesse momento a saúde segue a teoria flexineriana, de modelo biologicista, que coloca a doença como foco da atenção seguindo a linha curativista e mecanicista. Na prática concretizou o modelo médico assistencial privatista, centralizando a saúde na figura do médico e tornando a saúde instrumento de comércio, inserida no bojo de um Sistema médico industrial.

Brasil (2006) relaciona os achados de Bertolli-filho (2003) relatando que nos vários momentos históricos o sistema capitalista ofereceu apoio à saúde da população como uma forma de manutenção da força de trabalho produtiva para suprir os interesses econômicos e não com intuito de ofertar qualidade de vida ao povo.

Reforma Sanitária à consagração do SUS (1998): a partir do contexto de injustiças e repressão, vivenciado na ditadura militar, a massa da população através de movimentos sociais e grupos de profissionais de diversas áreas do conhecimento se posicionaram contra a ação militar e passaram a reivindicar a representatividade do povo no processo de saúde.

As manifestações populares pregavam a ideia de que toda a população tinha direito a saúde de qualidade e de que o estado devia assumir a responsabilidade por promover políticas públicas de saúde ao invés de privatizar um bem público. A partir dessa organização popular o Brasil se encontrou realizando o movimento da Reforma Sanitária que exigiu um novo arcabouço institucional voltado para saúde. Esse processo de luta de classes em busca da saúde pública ganhou novos horizontes com as conferências de saúde, em especial com a $8^{\circ}$ Conferência Nacional de 
Saúde (1986) e finalmente com a consolidação em nível constitucional (1988) de um sistema público de saúde: o Sistema Único de Saúde (SUS) consagrado em 1998.

SUS e as novas concepções de saúde: para Brasil (2006) e Bertolli-filho (2003), o advento do SUS proporciona um novo olhar sobre a saúde não mais como a mera ausência de doença, mas sim como um estado de bem-estar biopsicossocial dos indivíduos, que são interpretados de uma forma totalizante e não como máquinas a serviço da produção econômica.

Segundo os autores, a atenção em saúde passa a ser articulada em diferentes níveis nos quais as equipes multiprofissionais de saúde atuam para ofertar tratamento humanizado aos usuários, que merecem ter seus direitos atendidos a partir dos princípios e diretrizes do SUS.

Como um dos objetivos da educação em saúde é a efetivação do SUS, Galvão (2017) destaca que a organização e o trabalho da gestão responsável pelo programa da Residência, em questão, é um fator determinante para que a formação desenvolvida consiga respeitar e praticar os princípios e diretrizes do SUS.

Sabendo que o SUS se desenvolve também em outras esferas da saúde pública, um desafio para a Residência seria oferecer parte da formação multiprofissional em traumatologia e ortopedia na Atenção Básica para que os residentes atuem em todos os níveis de atenção.

Mendes et al (2011) destacaram a experiência de uma Residência Multiprofissional em Saúde de um hospital universitário na cidade de Salvador- Bahia, o qual desenvolveu um plano pedagógico com rodízios entre grupos de residentes para atuar na área hospitalar e na atenção básica, através da associação entre teoria e prática.

Segundo o autor, os relatos dos residentes sobre a atuação na Atenção Básica foram positivos, pois viram a realidade de saúde num contexto diferente, tendo a oportunidade de repensar seus papéis enquanto profissionais de saúde; vivenciaram a multidisciplinaridade e interdisciplinaridade em equipe; exercitaram a ética profissional a partir de 
novos dilemas encontrados na Atenção Básica e ajudaram a construir projetos e ações para promover saúde a partir da necessidade da comunidade atendida nessa esfera de Atenção.

Cumprir os princípios e diretrizes do SUS em todos os níveis de atenção representa também a perpetuação do processo de conquistas das lutas sociais instauradas no Brasil no campo da saúde pública. Mioto (2012) cita que um dos desafios das Residências multiprofissionais é a manutenção contínua de fidelidade ao movimento da Reforma Sanitária, que incorporou a teoria marxiana na análise crítica das condições de saúde da população diante da estrutura capitalista.

\section{CONCLUSÃO}

O estudo em questão evidenciou algumas falhas na organização da Residência Multiprofissional analisada no que diz respeito aos recursos pedagógicos instituídos, ao comprovar a falta de acesso ao PPP por parte dos preceptores e pelo conteúdo superficial e conciso deste, como comprovado por Galvão (2017).

Essa constatação evidencia a necessidade da articulação da gestão do programa em não somente oferecer o acesso, mas incluir os preceptores na discussão tanto do PPP quanto do currículo por meio de encontros constantes que até o presente momento não existem com frequência, como afirmado pela maioria dos preceptores. Além disso, é preciso o investimento na EPS em vista da qualificação desses profissionais, que em sua maioria não possuem nenhum curso voltado para a preceptoria.

A atualização frequente a respeito da Ortopedia e Traumatologia, o conhecimento e aplicação das metodologias ativas de ensino pela grande maioria dos preceptores, representa um avanço na educação em saúde, pois na tarefa de facilitador, segundo a ABEM (2013), o exercício da preceptoria está no estímulo à formação crítica, na reciclagem dos métodos de ensino e conhecimentos para seu próprio amadurecimento e 
contribuição no processo de ensino e aprendizagem já que são tidos como referência pessoal e profissional principalmente pelos residentes.

Através das discussões é possível visualizar que os preceptores compreendem que a educação não se dá apenas pela transmissão de conhecimentos na construção do saber e ao identificarem a união da interdisciplinaridade e multidisciplinaridade nas discussões de casos clínicos, somado ao fato que de acordo com a maioria deles a Residência está nos moldes dos princípios e diretrizes do SUS, percebe-se que o programa implantado há poucos anos já preconiza desde cedo as mudanças na realidade social da região que abrange.

É importante salientar como limitações do estudo o fato do questionário ser quantitativo, dessa forma, o estudo não permite um entendimento mais ampliado sobre a percepção dos preceptores a respeito do ensino e aprendizado contido na Residência ou ainda limita-se por não explorar detalhadamente aspectos da formação desses profissionais, que podem repercutir na atuação enquanto preceptores da Residência. Por essas razões e em nome da necessidade de novas evidências científicas que abordem essa temática, escassa na literatura a nível regional, é importante o delineamento de novos estudos nessa vertente de pesquisa.

Finalmente, investigar a opinião dos preceptores acerca do Projeto Político Pedagógico, identificar o interesse destes quanto ao crescimento em sua própria formação profissional e atuação enquanto preceptor, verificar o nível de entendimento sobre as metodologias ativas de ensino e ainda averiguar a suas opiniões sobre a atenção multidisciplinar e interdisciplinar no cumprimento dos princípios e diretrizes do SUS, corresponde a uma forma de não somente apontar e comprovar alguns déficits, mas acima de tudo utilizar tais falhas como base de melhorias na educação em saúde e, consequentemente, aumentar a qualidade do serviço biopsicossocial prestado à população da região do Baixo Amazonas. 


\section{REFERÊNCIAS}

ABEM. Associação Brasileira de Educação Médica. Cadernos da ABEM: O preceptor por ele mesmo, v.9, 2013.

ALEXANDRE, M.G. Ética e Bioética no processo de ensino-aprendizagem na residência em saúde. 2013. 41f. Monografia (Especialização em Práticas Pedagógicas em saúde do EDUCA SAUDE) - Universidade Federal do Rio Grande do Sul, Porto Alegre, 2013.

BARROS, C. M. Papel do preceptor na residência multiprofissional: experiência do serviço social. Porto Alegre: 2010. 43 f. (Especialização em práticas pedagógicas para a educação em serviços de saúde) Universidade Federal do Rio Grande do Sul.

BRASIL, Ministério da Saúde. A Construção do SUS: História da Reforma Sanitária e do processo participativo. Brasília: Editora MS, 2006.

BERTOLLI-FILHO, C. História da saúde pública no Brasil. São Paulo: Ática, 2003.

BERBEL, N. A. N. As metodologias ativas e a promoção da autonomia de estudantes. Revista Semina: Ciências Sociais e Humanas, v.32, n.1, p. 25-40, 2011.

BERBEL, N. A. N. A problematização e a aprendizagem baseada em problemas: diferentes termos ou diferentes caminhos? Revista Interface Comunicação, Saúde, Educação, n.2, v.2, p.139-154, 1998.

BISPO, E. P. F; TAVARES, C. H. F; TOMAZ, J. M. T. Interdisciplinaridade no ensino em saúde: O olhar do preceptor na Saúde da Família. Revista Interface Comunicação, Saúde, Educação, v. 18, n.49, p.337-350, 2014.

CANTANI, S. D.; JENERAL, R. B. R. Abrindo o caminho para a residência multiprofissional em Saúde da família através da metodologia ativa de Aprendizagem em um município do interior do estado de são Paulo: relato de experiência. In Conferencia Internacional - problem- based learning and active leading methodologies, 2016, São Paulo. Anais... São Paulo, 2016.

CECCIM, R. B. Educação Permanente em Saúde: desafio ambicioso e necessário. Revista Interface-Comunicação, Saúde, Educação, v.9, n.16, p.161-77, 2005.

COHEN, Y. O. O século de Taylor, Lenin e Freud. Revista Tempo Social, v. 24, n.12, p. $211-232,2012$.

DAVINI, M. C. Enfoques, Problemas e Perspectivas na Educação Permanente dos Recursos Humanos em Saúde. Política Nacional de Educação Permanente em Saúde. Série pacto pela saúde. v.9, p.39-59, 2009.

EZEQUIEL, M. C. D. G. et al. Estudantes e Usuários Avaliam Ferramenta de Educação Permanente em Saúde - Sieps. Revista Brasileira de Educação Médica, v.1, n.2, p.112-130, 2012. 
FILHO, W. D. L. O mito da subalternidade do trabalho da enfermagem à medicina. Pelotas: Editora e Gráfica Universitária, 2004.

FOULCAULT, M. Microfísica do Poder. Rio de Janeiro: Graal, 2001.

FOUCAULT, M. A hermenêutica do sujeito. São Paulo: Martins Fontes, 2006.

FREIRE, P. Pedagogia do Oprimido. Rio de Janeiro: Paz e Terra, 2005.

FONSECA, M. G; ROCHA, A. L. F. Perspectivas do trabalho em saúde. Uma visão do modelo biomédico e o trabalho interdisciplinar. Revista Digital EFDesportes.com. v. 17, n. 173, 2012.

FEUERWERKER, L. C. M; SENA, R. R. Interdisciplinaridade, trabalho multiprofissional e em equipe. Sinônimos? Como se relacionam e o que têm a ver com a nossa vida? Revista Olho Mágico. V.5, n.18, p.5-6, 1999.

GALVÃO, C. P. A gestão do Ensino da Residência Multiprofissional em Saúde no HRBA. Santarém: Contribuições para a consolidação da cultura de Hospital Ensino na Amazônia. 2017. Dissertação (Mestrado em Educação) Universidade Federal do Oeste do Pará, Santarém, 2017.

GASPARIN, J. L.; PETENUCCl, M. C. Pedagogia histórico crítica: da teoria à prática no contexto escolar. 2009.

GELBCKE, L. F.; MATOS, E.; SALLUN, C. N. Desafios para a integração multiprofissional e interdisciplinar. Revista Eletrônica Tempus - Acta de Saúde Coletiva, v.6, n.4, p. 31-39, 2012.

GOMES, M. C. J. O Atual Ensino da Ética para os Profissionais de Saúde e seus Reflexos no Cotidiano do Povo Brasileiro. Revista Bioética, v.4, n.1, 2009.

GUIMARÃES, T.G. Papel do preceptor na residência multiprofissional: experiência da nutrição. 2010. 40f. Monografia (Especialização em práticas pedagógicas para a educação em serviços de saúde) - Universidade Federal do Rio Grande do Sul, Porto Alegre, 2010.

HADDAD, J. G. V.; ZOBOLI, E. L. C. P. O sistema único de saúde e o giro ético necessário na formação do enfermeiro. Revista O Mundo da Saúde, v. 34, n.1, p.86-91, 2010.

HONDA, K.; CHIRRELI, C. M. Residência Multiprofissional em Saúde: formação com metodologias ativas de ensino-aprendizagem. Indagatio Didactica, v. 7 , n.3, 2015.

LIBÂNEO, J. C. Democratização da Escola Pública: a pedagogia crítico-social dos conteúdos. São Paulo: Loyola, 1986.

LOPES S. R. S. et al. Potencialidades da Educação Permanente para a transformação das práticas de saúde. Com Ciências Saúde, v. 2, n.18, p. 147155, 2007.

LUZ, F. M. Educação Permanente em Saúde (EPS): Uma estratégia que possibilita transformações no processo de trabalho. Monografia (Curso de 
Especialização em Atenção Básica em Saúde da Família) - Universidade Federal de Minas Gerais, Varinhas, 2010.

MAGALHÃES, A.B. et al. Percepção, Interesse e conhecimento de docentes de fisioterapia sobre a ética na profissão. Revista Bioética, v.24, n.2, p. 322331, 2016.

MARQUES, G.; LIMA, M. A. D. S. Organização tecnológica do trabalho em um pronto atendimento e a autonomia do trabalhador de enfermagem. Revista da Escola de Enfermagem da USP, v. 42, n.1, p. 41-47, 2008.

MEDEIROS, A. C. D. et al. Gestão participativa na educação permanente em saúde: olhar das enfermeiras. Revista Brasileira de Enfermagem, v. 63, n. 1. p. 38-42, 2010.

MASHIBA, G. C. X.; MENEZES, M. . B. O processo histórico da pedagogia histórico-crítica: gênese, Desenvolvimento e organização didáticometodológica. In Seminário nacional de estudos e pesquisas "história, sociedade e educação no Brasil", 2012, João Pessoa. Anais... João Pessoa: Universidade Federal da Paraíba, 2012. p.4516-4527.

MENDES, L. C. et al. Relato de experiência do primeiro ano da residência multiprofissional hospitalar em saúde, pela ótica da Psicologia. Revista Sociedade Brasileira de Psicologia Hospitalar, v.14, n.1, 2011.

MIOTO, R. C. P. et al. As residências multiprofissionais em saúde: a experiência da universidade federal de Santa Catarina. Revista Serviço Social \& Saúde, v. 11 , n. 2, p. 185-209, 2012.

MOREIRA, B. H. A pedagogia histórico-crítica no contexto educacional brasileiro: reflexões preliminares numa abordagem histórica, teórica e prática. X ANPED SUL, Florianópolis, outubro de 2014.

SAVIANI, D. Escola e Democracia. Campinas, São Paulo: Autores Associados, 2005.

SAVIANI, D. A pedagogia histórico-crítica. Revista Binacional Brasil Argentina, v.3, n.2, p.11-36, 2014.

ROCHA, H. C.; RIBEIRO, V. B. Curso de Formação Pedagógica para Preceptores do Internato Médico. Revista Brasileira de Educação Médica, v.36, n.3, p.343-350, 2012.

ROVERE, M. Comentarios estimulados por la lectura del artículo "Educação PERMANENTE em Saúde: desafio ambicioso e necessário". Revista Interface Comunicação, Saúde, Educação, v.9, n.16, p.161-77, 2005.

RAMOS, F. R. S et al. A ética que se constrói no processo de formação de enfermeiros: concepções, espaços e estratégias. Revista Latino Americana de Enfermagem, v.21, p. 1-9, 2013.

SANTOS, A. C. B et al. Antropologia da saúde e da doença: contribuições para a construção de novas práticas em saúde. Revista NUFEN, v.4, n.2, p.1121, 2012. 
SANTOS, S. S. S. C. et al. Interdisciplinaridade: a pesquisa como eixo de formação/profissionalização na saúde/enfermagem. Revista didática Sistêmica, v.7, 2007.

SANTOMÉ, J. T. Globalização e interdisciplinaridade: o currículo integrado. Porto Alegre: Artmed, 1998.

SAUPE, R.; CUTOLO, L. R. A.; SANDRI, J. V. A. Construção de descritores para o processo de educação permanente em atenção básica. Trabalho, Educação e Saúde, v.5, n.3, p. 433-452, 2008.

SAVIANI, D. Escola e Democracia. Campinas, São Paulo: Autores Associados, 2005.

SAVIANI, D. Pedagogia histórico-crítica: primeiras aproximações. Campinas, SP: Autores Associados, 2003.

SHARE, T. Metodologia do ensino na preceptoria da residência médica. Revista do Medico Residente, v.4, n.2, p. 116-120, 2012.

SOARES, M. de S. Médicos e mezinheiros na corte imperial: uma herança colonial. História, Ciências, Saúde, v.8, n.2, p.407 - 38, 2001.

TENORIO, F. G. A unidade dos contrários: Fordismo e Pós-Fordismo. Revista de Administração Pública, v. 45, n.4, p. 1141-1172, 2012.

VEIGA, I. P. A. Projeto político-pedagógico da escola: uma construção possível. Campinas, SP: Papirus, 2007.

YAJAHUANCA, R. A.; DINIZ, C. S. G.; CABRAL, C. S. É preciso "ikarar os kutipados": interculturalidade e assistência à saúde na Amazônia Pervana. Revista Ciência \& Saúde Coletiva, v.20, n.9, p.2837-2846, 2015.

Recebido em: Maio de 2017 Aprovado em: Outubro de 2017 